\title{
INFLATION AND MONETARY POLICY IN APRIL 2013
}

\author{
A.Bozhechkova
}

In April 2013 the consumer price index made 0.5\% (versus 0.3\% in April 2012), which is by 0.2 p.p. higher than in March of this year. In May inflation was also growing: in the 20 days of the month the CPI reached $0.4 \%$. As a result, the inflation rate in annual terms has exceeded $7.2 \%$. In Q1 2013, according to the tentative estimates of the Bank of Russia, the net outflow of capital from the country amounted to $\$ 25.8 b n$, which is by $\$ 7.8 b n$ less than in 2012

In April consumer price inflation accelerated in Russia: the index of consumer prices for the month results has grown from $0.3 \%$ in March to $0.5 \%$, having increased the indicator of 2012 by 0.2 p.p. As a result, the inflation rate in annual terms has reached $7.2 \%$ (against $7.0 \%$ in April of the last year) (See Fig. 1). The core inflation ${ }^{1}$ in April 2013 made 0.4\%, which coincides with the relevant indicator of the last year

The CPI growth was contributed, first of all, by an increased rates of food prices (from $0.4 \%$ in March to $0.7 \%$ in April). The reasons for this were an increase in the rate of prices for fruit and vegetables (from $0.1 \%$ in March to $3.6 \%$ ), eggs (from $0.2 \%$ in March to $3.4 \%$ ), and sugar (from -0.8 $\%$ in March to 1.7\%). Prices for the foods, such as meat and poultry, as well as sunflower oil, compared with the previous month, were lower respectively by $0.9 \%$ and $0.2 \%$. At the same time, there was continued a decline in the rate of growth in prices for alcoholic beverages from $2 \%$ in February and 1.4\% in March to 1.0\% in April, bread and bakery products from 1.4\% in February and March to $0.8 \%$ in April and pasta from 1.7\% in February and 1\% in March to $0.6 \%$ in April.

The growth rate of prices and tariffs for commercial services to the population in April made $0.5 \%$, being higher than in March (0.2\%). The cost of pre-school education services in April has grown by $2 \%$. Services of foreign travel have grown, the price of which increased by $1.6 \%$, as well as passenger transport services, the prices of which rose by 1\%: it he cost of fixed-route taxi-vans, subway, compartment cars of branded long-distance trains, as well as prices for air transport services have been increased. Growing dynamics was observed also in prices for household services $(+0.9 \%)$, health care $(+0.9 \%)$ and insurance services $(+0.8 \%)$.

In April the rate of price growth for non-food products as compared with March and April of the last year has not changed, making for the month $0.4 \%$.The greatest growth in this product group made prices (by $+4.3 \%$ ), medicines (by $1.0 \%$ ) and footwear (by $+0.4 \%$ ). Among the non-food items reduction was observed in April for video and audio goods (by -0.4\%) and gasoline (by -0.3\%).

As of 20 days of May, the CPI made $0.4 \%$. As a result, the accumulated since the beginning of the year inflation reached $2.8 \%$, which is by 1.3 p.p. higher than at the same period of 2012 . The annual inflation rate for May 20 made $7.2 \%$

We would like to note that the acceleration of inflation at the beginning of the year seems to have a monetary nature and is a consequence of the seasonal growth in prices for food products, increase of the excise tax on excisable goods and tariffs for transportation services at the beginning of the year. Some role in rising prices was also played the February indexation of pensions. Decline in consumer inflation began in February and continued in March, but in April the trend of price growth, associated with the rising costs of some food staffs and the dynamics of tariffs and prices for certain types of services was noted. Further pressure on prices in terms of their growth will be provided by indexing of housing utility tariffs from July 1 and expectations of a poor harvest due to the difficult weather conditions in spring. The constraining factors in inflation will be a decline in domestic demand, which is observed since through-out the whole year, and the continued slowdown in monetary supply (M2 growth rate has been slowed down in the annual terms from

1 The core consumer price index is the indicator reflecting the level of inflation in the consumer market after adjustment for the seasonal (prices of vegetable and fruit products) and administrative (regulated tariffs for certain types of services, etc.) factors, which is also calculated by the RF Statistical Service (Rosstat). 


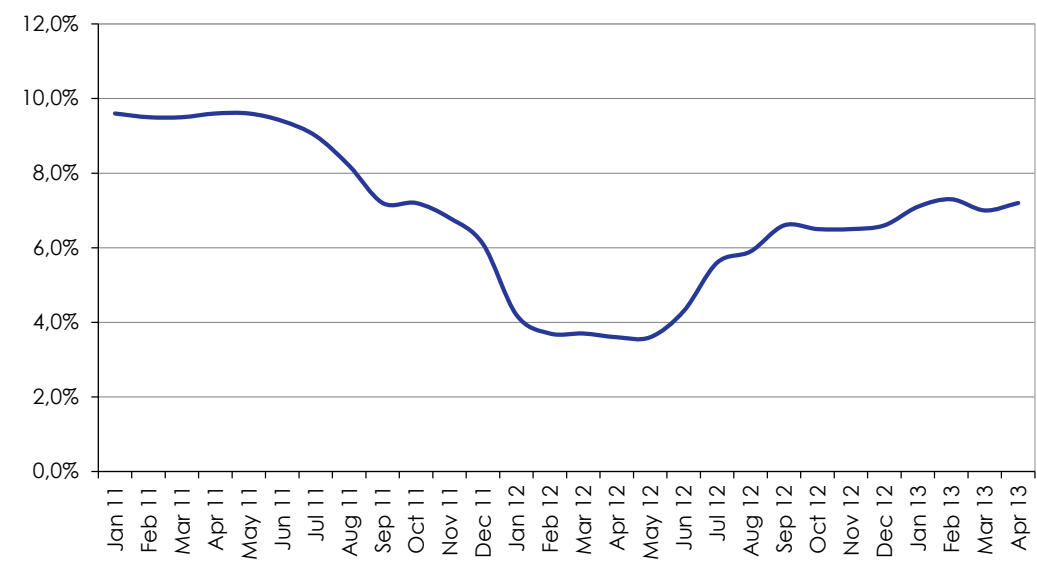

Source: RF Statistical Service.

Fig. 1. The Growth Rate of CPI in 201 1-2013 (\% year to year)

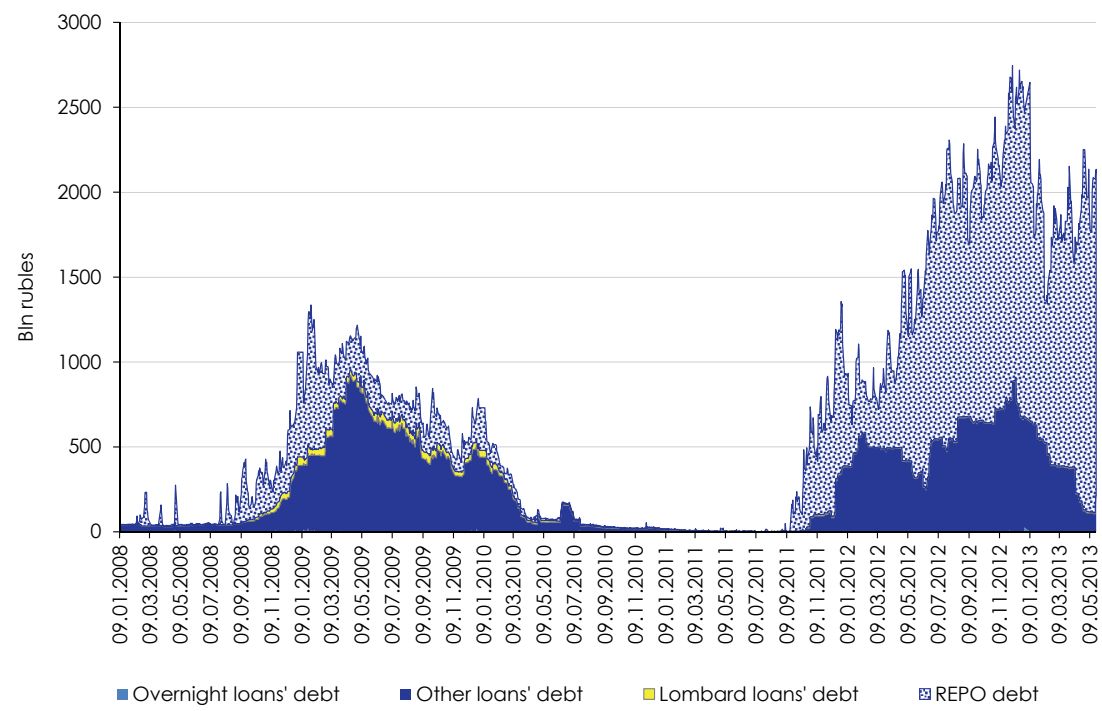

Fig. 2. Arrears of commercial banks with the Bank of Russia in 2008-2013.

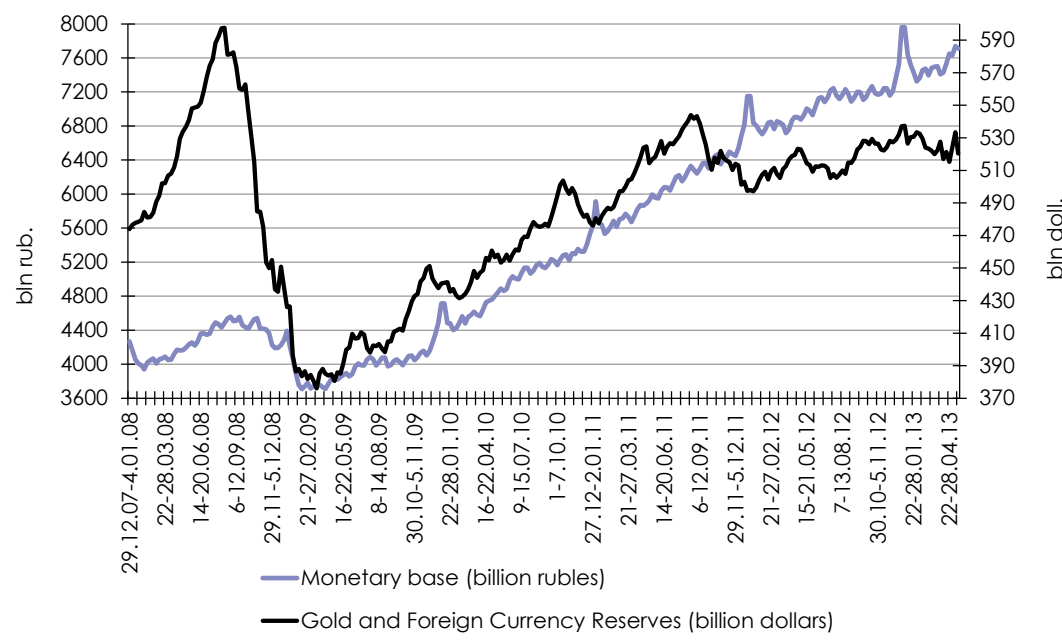

Fig. 3.Dynamics of the monetary base (in narrow definition) and gold (international) reserves of the Russian Federation in 2007-2013
$21.2 \%$ on 1 April 2012 to $14.6 \%$ on April 1, 2013).

In April 2013, the expansion of the broad monetary base was continued. As of the month results, it increased by $2.1 \%$ to Rb 8.8109 trillion (Fig. 2). The growth of the monetary base in broad terms is due to the increase in the volume of cash in circulation with regard to the cash balances of credit institutions by $4.3 \%$ to $\mathrm{Rb} 7,410.3$ trillion and required reserves by $\mathrm{Rb} 5.4 \%$ to $\mathrm{Rb}$ 473.7bn. Herewith, the correspondent accounts decreased by $4.8 \%$ to $\mathrm{Rb} 814.9 \mathrm{bn}$, banks' deposits with the Central Bank - by $49.1 \%$ to $\mathrm{Rb} 112.1 \mathrm{bn}$.

The simultaneous growth of cash in circulation and mandatory reserves in April has resulted in the expansion of the monetary base in narrow definition (cash plus mandatory reserves) by $4.4 \%$ to $\mathrm{Rb}$ 7,884 trillion (Fig. 3).

In April the volume of excessive reserves of commercial banks ${ }^{1}$ has decreased by $13.9 \%$ to $\mathrm{Rb} 927 \mathrm{bn}$. Herewith, the debt of banks under repo agreements in April has increased by $32.9 \%$ to Rb 2.06 trillion, remaining at that level until the end of May (Fig. 2). Lower liquidity in the banking sector have contributed to the quarterly tax payments and the increase in the share of cash in the monetary supply on the eve of May Day, which has provoked an upward pressure on the interbank rates ${ }^{2}$ from $6 \%$ in March to $6.2 \%$ in April. From May 6 to 20 this rate made $6.38 \%$ on average.

On May 1, 2013 the volume of international reserves of the RF Central Bank amounted to $\$ 533 \mathrm{bn}$, having decreased from the beginning of the year by $0.8 \%$. Reduction of the Russian foreign reserves in dollar terms was due

\footnotetext{
1 Under the excessive reserves of commercial banks with the RF Central Bank is understood the sum of correspondent accounts of commercial banks, their deposits with the RF CB and the RF CB bonds of commercial banks.

2 Interbank rate is an average MIACR rate of 1-day interbank loans in rubles.
} 
to the strengthening of the dollar against the Euro due to the problems in the economy of Cyprus. Note, that in April the RF Central Bank was performing foreign exchange interventions: the Bank of Russia has sold $\$ 663.06 \mathrm{~m}$ and Euro $45.05 \mathrm{~m}$ to decline volatility of the exchange rate during periods of its rapid reduction (Fig. 4).

According to the tentative estimates of the Bank of Russia, the net outflow of capital in QI of 2013 amounted to $\$ 25.8 \mathrm{bn}$, which is by $23.2 \%$ less than in 2012, when the outflow reached $\$ 33.6 \mathrm{bn}$. The slowing down of capital outflow is due primarily to the decline of the surplus balance of the current account of payments: a stable ruble nominal exchange rate with minimal interventions of the RF Central Bank indicates the balance of supply and demand in the foreign exchange market, at which the surplus on the current account offsets the negative balance in the financial account of balance of payments.

In April the ruble real effective exchange rate has decreased against foreign currencies by $1.5 \%$ (Fig. 4). At the same time, in as of the four months of the year, the ruble real effective exchange rate has increased by $2.9 \%$.

Due to the economic recession in the European Union, as well as reports on a possible tightening of the Federal Reserve System policy and mitigating the ECB policy, the Euro rate in the world currency market declined on May 21 to the level of $\$ 1.28$ against $\$$. During the first half of May the U.S. currency has grown up by $1.2 \%$ to Rb 31.4; however, in the second half of May, there was a decline in its rate to $\mathrm{Rb} 31.1$. Euro exchange rate has decreased WHEN? by1.1\% to Rb 40.2. As a result, the value of the currency basket has been decreased and on May 22 made Rb $35.2(-0.3 \%)$. 